University of Wollongong

Research Online

Faculty of Social Sciences - Papers (Archive) Faculty of Arts, Social Sciences \& Humanities

2015

Using facebook as a space for storytelling in geographical research

Anna de Jong

University of Wollongong, aldj998@uowmail.edu.au

Follow this and additional works at: https://ro.uow.edu.au/sspapers

Part of the Education Commons, and the Social and Behavioral Sciences Commons

Research Online is the open access institutional repository for the University of Wollongong. For further information contact the UOW Library: research-pubs@uow.edu.au 


\title{
Using facebook as a space for storytelling in geographical research
}

\begin{abstract}
Geographers have long been alert to the ways space matters to knowledge production and the stories participants choose to share. Despite such understandings, however, geographers remain surprisingly absent from discussions regarding the ways these concerns play out across online spaces. This article reflects on the employment of one online space, Facebook, as a site for storytelling in research exploring return journeys to two Australian festivals - the Big Day Out and Mardi Gras Parade. This article argues that insight over longer temporalities and shifting spatialities afforded through Facebook facilitates heightened understandings of the nuances, repetitions, differences and paradoxes of identities, encounters, and politics. Facebook, therefore, has the potential to allow for different ways of knowing that cannot be ascertained in more orthodox research spaces. Moreover, the slipperiness of conceptualisations of privacy and consent in this space draws attention to the necessity of understanding consent as fluid and ongoing, rather than antecedent to fieldwork commencement. Crucially, however, reconceptualisations of privacy and consent in this space expose potential obstacles university ethics committees may meet in responding to research moving online.
\end{abstract}

\section{Keywords}

research, geographical, storytelling, space, facebook

Disciplines

Education | Social and Behavioral Sciences

\section{Publication Details}

De Jong, A. (2015). Using facebook as a space for storytelling in geographical research. Geographical Research, 53 (2), 211-223. 


\section{Using Facebook as a space for storytelling in geographical research}

\section{Introduction}

Space matters to knowledge production and storytelling. A consideration, to which, geographical research has long been alert to (Bain and Nash, 2006; Datta, 2008). Geographers, however, remain surprisingly absent from discussions regarding how such concerns play out across online spaces. Instead, interest has generated from the abundance of online data that is already 'there for the taking' (Hine, 2005; Pickerill, 2007), and discussing the ethical dilemmas arising from using this 'freely available' information (Madge, 2007; Morrow et al., 2014). Geographers who have assessed the processes of fieldwork online have tended to compare online methods to their offline equivalents (Crooks, 2006; O'Conner et al., 2008), conceptualising 'the internet' as a monolithic entity, rather than exploring the unique social conventions and affordances across different online spaces.

Recent geographic work within critical technology studies has crucially recognised the inextricable linking of on and offline spaces (Graham et al. 2012; Wilson, 2011). Such conceptualisations are offering distinct understandings of how the digital is implicated in the production of knowledge. These renderings have tended to conceptualise the internet as an object to be studied, rather than method, to examine the ways both researcher and participant produce research within online spaces. Moreover, geographic critical technologies scholars have remained closely tied to simplified meta spatial ontologies of the geotag (although this is slowly shifting cf. Crampton et al., 2013), and are primarily concerned with issues of privacy, surveillance, power and representation. While such considerations are imperative when engaging with online spaces, I suggest geographers ought to move beyond problems, to productively reimagine the ways online spaces may be incorporated as sites for methodologies.

Media, communication and cultural studies scholars are at the forefront of discussions concerned with exploring difference across online spaces. Focus includes, but is not limited to, analysis of the ways identity is represented and enacted across online spaces (Gatson, 2011; Robards, 2012), (re)negotiations of intimate relations (Bakardjieva, 2005; Gregg and Driscoll, 2008) and the practices of online attention and participation, conceptualised as 'lurking' (Lee et al., 2006), and more recently, 'listening' (Crawford, 2009a, 2009b). Within this body of work, however, there is only limited exploration into the processes of fieldwork and narration of stories online, and the embeddedness of researchers within online spaces (see for exception Olive, 2012). 
In what follows I discuss one online space as a communication technology, to explore the expectations and social norms that influence the ways storytelling and research relations take place differently within this space. I begin by briefly outlining a project formulated as a rejoinder to the tendency within festivals research to focus on the forging of identities exclusively within the timeframe of the event, explain why and how online spaces were incorporated into the research design, and discuss storytelling as a geographical qualitative method. Section three, introduces the field site - Facebook. To consider the usefulness of Facebook as a field site I turn to successively explore four interconnected themes: 'temporality', 'power, privacy, identity and ethics', 'representation' and 'storytelling'. I conclude that understanding the ways storytelling, and fieldwork more broadly, takes place differently, through the unique social conventions and affordances across online spaces, may enable geographers to incorporate online communication technologies into research designs more effectively, in diverging and powerful ways. Table 1 provides a summary of Facebook's conventions and affordances outlined in this article, which influenced the process of storytelling and research relations.

\section{Research context and methods}

Within event tourism and management scholarship, festivals and events are frequently conceptualised through positivist frameworks as closed, fixed spaces with tightly defined boundaries. Consequently, such research tends to be predominately focused on themes relevant to the immediate temporal specificity of the event (cf. Pegg and Patterson, 2010). Dominant themes include, for example, attendance motivation, economic impacts, and marketing and management (Getz, 2010). Such themes tend to focus on the hedonistic elements of events, rather than recognising festivals as complex spaces producing different and often conflicting configurations of identity, place and belonging (Duffy, 2009). Such scholarship disembodies festival attendees, conceptualising the festival goer as rational, universalised and self-knowing (cf. Li and Petrick, 2006). Scholars have recently started attending to festivals as processual (Picard and Robinson, 2006), embodied (Johnston, 2007), and political (Browne, 2007). Influenced by these recent turns, the aim of the research project was to move beyond event time-space to explore the journeys of attendees to large metropolitan events. I argue that meaning and belonging as individual and collective identities has the potential to emerge through embodied and sensuous experiences of the spatial relationships that comprise return journeys, as much as within the temporal-spatiality of events.

To explore the sensuous, emotional and discursive experiences of return journeys I utilised a range of qualitative research methods. Before and after semi-structured storytelling, solicited diaries and self-directed photography, and participant observation enabled critical understanding of the shifting, 
nuanced and complex knowledges of festival experience. Following England $(2006,291)$ a mixed methodology was employed to attempt to keep the research 'sensitive to a range of questions and debates'. Understanding knowledge as partial, local and embodied (Moss, 2002), and aiming to explore the processual, embodied and political dimensions of festivals, I was interested in generating thicker descriptions (Geertz, 1973), over longer temporalities and shifting spatialities as part of the research, rather than conducting 'traditional' one off interviews. This led me to Lorimer's (2003) concept of 'small stories', and the notion of storytelling more broadly (for overview see Cameron 2012). Within geography there is growing interest towards storytelling; that is, the telling of small, personal, intimate and mundane experiences. Geographers are excited by the relational and material elements of small stories as a way to focus on particularities and nuances, rather than emphasising large scale, systemic grand narratives. Insights into participants' festival stories hold the potential to be both irreducibly personal, and expressions of broader social and political contexts. Before entering the field I anticipated that attempts to explore the 'small' stories of participants may help to question the universal hegemonic systemic claims that dominate event tourism and management literature - positioning festivals and events as closed fixed spaces, with tightly defined boundaries, and those who attend as rational, universalised and self-knowing.

Feminist geographers have long argued that knowledge production is influenced by the researcher's positionality (Rose, 1997). My identity is partial, fluid and constantly becoming. Conducting this project I became aware of how a sense of age, gender and ethnicity were sustained through my attendance at particular festivals and use of particular social media sites (specifically Facebook). I'm a 26 year old woman of middle class and European background. I use Facebook most days in varying ways, both for work and leisure. Being a full time PhD student with limited alternative time constraints, I not only have access, but also the power of flexibility, to use Facebook, blurring the boundaries between leisure and work time. Becoming 'friends' with participants on Facebook and sharing festival stories was not a premeditated decision, it unfolded as a result of my own everyday use of this site, alongside the converging ways many participants also used this space. 'Knowing' Facebook I was able to use this space in culturally appropriate ways.

Two festivals sites were selected for this project; Big Day Out ${ }^{1}$ and the Sydney Gay and Lesbian Mardi Gras ${ }^{2}$. Pilot research was carried out with 14 participants ( 8 women, 6 men) journeying to the

\footnotetext{
${ }^{1}$ The Big Day Out is one of Australia's longest running music festivals, first occurring in 1992. In 2013 the touring festival visited Adelaide, Gold Coast, Melbourne, Perth and Sydney, selling 201,000 tickets nationally. Big Day Out was cancelled for 2015 on 26 June 2014. It is currently unknown as to whether the festival will return.
} 
Big Day Out music festival, while 19 individuals (14 women, 5 men) journeying to Mardi Gras participated in primary fieldwork. For both events participants were recruited through an online survey (advertised through Facebook, Twitter and relevant forums) and word of mouth. Participants live in a variety of situations and configurations. They have varying degrees of education and are employed in a range of occupations. Participants' ages vary from late teens to early twenties, and early twenties to early forties, for Big Day Out and Mardi Gras Parade respectively. They live in a multitude of places, across Australia and New Zealand and vary in ethnicity and religious belief. Those who chose to undertake storytelling online had the time, financial resources and ability to access and use this space.

Following recruitment for the Big Day Out, participants were provided with the choice for storytelling to take place through three online mediums; email, Facebook or Skype. Face to face interviews were not an option for pilot fieldwork for two reasons. First, budget constraints, alongside the Australia wide geographical dispersion of participants, necessitated communication to take place online. Secondly, and more importantly, I was interested in piloting the potential of different online spaces in eliciting processual, embodied and political stories without the incorporation of face to face contact. Storytelling with the 19 participants attending Mardi Gras were more amorphous, as a result of the mixed success of storytelling through certain online spaces in pilot fieldwork - before and after storying taking place through varying combinations of Skype, Facebook and face to face. For both the before and after interviews, storytelling was loosely structured through five themes: planning, the outward journey, the event, the return journey and afterwards. The interviews aimed to follow topics of conversation largely determined by participants. Follow up interviews also incorporated themes from participants' solicited diaries and self-directed photography produced during the return journey, alongside my own participant observation. Despite attempts to allow participants to shape the flow of storytelling, important variations occurred regarding the ways stories were shared across the three online mediums: Facebook, Skype and email. This article takes Facebook as its focus because particularly novel insights into participants' journeys, alongside unique understandings of the processual, embodied and political elements of festival experience, emerged through Facebook.

\section{Facebook -the field site}

Facebook is a social networking site that reached 1.1 billion users in 2013 (Facebook, 2013), and is used by 9 million Australians everyday (Ross, 2014). It is the number one ranked website in the

\footnotetext{
${ }^{2}$ The Sydney Gay and Lesbian Mardi Gras Parade originated as a political protest in 1978. Over one hundred floats and individual entries make the parade. While Mardi Gras Parade is an open event, annual attendance numbers are estimated to hover around 300,000.
} 
world (Alexa, 2013). To that end, Facebook, and social networking sites more broadly, have transformed our ability to communicate. Geographers are only beginning to recognise this, acknowledging that the site's inherently social design, high numbers of everyday users and particular modes of belonging creates a unique space to engage with participants (Kitchin et al., 2013; Waitt and de Jong, 2013). In this project, Facebook interaction occurred in a combination of ways with ten of the thirty three participants. Communication involved everything from participants' simply adding me as a 'friend', to more in-depth, ongoing communications through private messages over a number of months, including sharing photos, video, and commenting on unrelated status updates and posts.

\section{Temporality}

Brown and Gregg (2012) propose social networking sites, such as Facebook, extend the pleasures of going out for a longer period. This claim, I suggest, should be extended to festival experiences, where sharing stories, following up with new bands and uploading photos becomes part of the temporalities of festival attendance. In this sense, Facebook is more than a space to engage with participants, it is part of the cultural context of festivals and events. Facebook has become part of who many people are, and is consequently crucial to the expression of identity (Adams and Ghose, 2003).

Implications arose from how I engaged with participants through Facebook; including dissipation of the performances of 'researcher' and 'researched' as both participants and I shared stories and acted out a collaborative storytelling process. This coalition contrasted with the ways storytelling often emerges during face to face interviews, which can be constrained in space and time, minimising the emergence of engagement and collaboration between researcher and participant.

Posting, uploading and commenting took place, in situ, while on the move - as part of the return journey and during events. Facebook was thus crucial to understanding how festivals become enveloped within spaces beyond that of their duration. This was particularly so for five participants who travelled 700 kilometres together by coach to Mardi Gras, as part of a larger regional queer collective. At the beginning of the journey one participant created an online survey ${ }^{3}$, linking the survey to the group's Facebook page, as a way to determine which movie to watch during the trip. Asking this question through Facebook, brought everyone on the bus into conversation, conversation that took place both on and offline, generating an atmosphere of belonging. Some of those on the bus, for example, humorously linked good and bad movie reviews in the survey's

\footnotetext{
${ }^{3}$ There are a number of Facebook apps that enable users to easily create surveys/polls.
} 
comments section in an attempt to sway other's votes. The in situ utilisation of the survey on the move is an interesting example of using an online space to become closer with those already physically proximate, rather than how it has often been understood within academia as a way to bring people together over distance (cf. Schwanen and Kwan, 2008).

Use of the smartphone on the move shifted the rhythms and temporalities of 'traditional' participant engagement, through the granting of simultaneous and in the moment access to participant experiences. The entanglement of Facebook and smartphone enabled participant contact to take on a more subtle, yet present, form as fieldwork became woven through everyday life. Access to participants in the moment experiences provided insight into the ways emotions shifted across spatialities and temporalities, creating knowledge of the processual aspects of festivals and participants' fluid embodied experiences. Having attended Big Day Out, Jess for example, posted the following morning 'anyone else feeling post-festival depression?' (Figure 1).

Using Facebook on the move illustrates an avenue for geographers to expand knowledge of how bodies move through space and capture the flow of experience. Attempting to use internet connection in large crowds at both Big Day Out and Mardi Gras Parade, however, became problematic as a result of the increased interference from too many phone signals within the one area. Similarly, the use of Facebook on the road was at times precarious because of limited internet connection across rural and regional Australia. Despite some difficulties with online access when on the move, the folding of Facebook and smartphone generate exciting opportunities for moving beyond spatial and temporal confines to explore the ways festivals, and tourist events more broadly, are part of much larger processes.

Many participants continued to keep in touch well beyond the formal confines of 'fieldwork', sharing different stories they felt might be relevant to the study. By way of example, Jack shared similar music preferences to myself and was beginning an honours thesis at the onset of fieldwork. Consequently, Jack continued to contact me with decisions concerning which music festivals he planned to (not) attend, and asked particular questions around the process of thesis writing. Sharing these commonalities generated ongoing conversations with Jack over a twelve month period that shifted into areas well beyond that of the original fieldwork themes, yet were deeply informative to the research in terms of understanding the entanglements of events and everyday life. Easily sharing my own knowledge about honours also enabled a way to give back and open up to participants. The continued sharing of stories was facilitated through the ease of remaining in contact, alongside the news feed's constant reminders of 'friends' everyday experiences, which served to draw individuals back into engagement (Nash, 2012). Emails sent by Facebook further drew me back into 
communication as I was instantly notified of birthdays, mentions, tags and messages - even when not signed into Facebook.

Through maintaining engagement and exchange with participants over longer temporalities, experiences and ideas were kept alive, moved, and formed alongside both theory and current geographic debates. This enabled these participants to take on more active roles in shaping and informing the research as it shifted over time. Crucially, however, generalisation should not be drawn from how participants used this online social media space. While these practices hint at Facebook's potential for storytelling and engagement, each participant used this site in complex and shifting ways, none of which independently represent the fabric of this space. Remaining mindful to varying forms of participation, and also to those choosing not to undertake storytelling through Facebook (23 of 33 participants), is crucial. Engaging in this space requires immense time to frame one's everyday life as meaningful, a certain literacy, and self-presentation - all of which may be uncomfortable or daunting to some, serving to exclude individuals from engaging in either Facebook research, or the space more generally.

Power, privacy, identity and ethics

A separate Facebook profile was not created for fieldwork, choosing rather to follow Driscoll and Gregg $(2010,19)$ in using my previously established account to 'volunteer the same sorts of information...as participants offer about themselves'. While creating a number of ethical negotiations, sharing my profile remained consistent with the ways diverse networks come together through this site (Robards, 2012) and enabled intimate communication in a way that may not have been possible through a more socially distant, professional profile. Sharing small pieces of information, as participants shared theirs, involved a degree of 'ambient intimacy' (Reichelt, 2007) I had not experienced during fieldwork in alternative spaces. Reichelt (2007) describes ambient intimacy as the ability to maintain a level of intimacy with people you might not otherwise keep in touch with because the time and space of particular online spaces conspire it; Facebook, for example, allowed me to know participants exercise regimes, what participants are eating for lunch and who is drinking with who, and where, this Friday night. It was the mundane, prosaic quality of this information, information generally shared only with those closest to us, which made it so intimate and personal (Crawford, 2009a).

Intimate exchanges problematised definitions of 'participant', 'non-participant' and 'researcher'. Logging onto Facebook, for instance, became a daunting experience, as over time I learnt more and more about the weight loss journeys, breakups, drunken nights out and 'food porn' choices of my 
participants, and their friends. Surveillance went both ways. Participants too were privy to my own information; to unknown degrees and with unknown consequences. While introducing new concerns around privacy for researchers, I suggest that this vulnerability goes some way to breaking down participant/researcher binaries, offering productive possibilities through the transfer of power to those being researched. Access to ambient intimacy also increases awareness of the ways festivals are processual, entangled with everyday life. I continue to communicate with some participants in complex and shifting ways not always relating to 'fieldwork'.

While Facebook enabled access to participants everyday lives, it was crucial to recognise which participants were being seen, and whose voices might be shadowed through coding in my news feed. Code produces Facebook, affecting our experience of this online space. The regulatory role of Facebook code played a powerful function in determining participatory engagement, and what content was available for viewing. Facebook feeds do not present information chronologically; rather information that generates further activity is prioritised, while information deemed to not generate activity has limited visibility on other's news feeds. Posts of particular, arguably more active 'friends' for instance are prioritised (Weber, 2010). Attempting to make sense of such coding was problematic because Facebook refuses coding transparency, raising important considerations concerning power and representation for researchers using social media as a site for fieldwork.

Negotiations around power, privacy, identity and ethics further arose through possibilities to access participants' archived posts, comments and images through profile pages. Access was productive in acquiring perceptions of broader life narratives and generated solutions to temporal issues in garnering 'thick descriptions' (Hammersley, 2006). Shifting temporalities of concealment and revelation, however, rendered dilemmas concerning the power of participants to control what is revealed through the research process (Elwood and Leszczynski, 2011; Dodge and Kitchin, 2009).

I became situated in a powerful position negotiating privacy and the wealth of information pertaining to participants and their extended social networks. In the first instance I felt the use of such information had to be openly and continually negotiated with participants. Through these negotiations, however, it emerged, that understandings of 'privacy' and disclosure had taken on alternative meanings within the context of Facebook, influencing what and how information was shared. Rather than simplistic binary understandings of content being either public or private, participants' privacy practices were nuanced, complex and considered. Particular aspects of information were shared in specific contexts, while complex practices were used to control which friends had access to specific information. 
Online participant observation is often perceived pejoratively within academia as 'lurking' (Lee et al. 2006; Nonnecke and Preece, 2003), or in social discourse 'stalking' (Berry, 2012; Lafata, 2014). Contrasting with conventional connotations of stalking and lurking as forms of unwanted monitoring, there was an understanding that profile pages would be accessed once becoming friends, with all uploaded information being filtered with awareness of this ethically permissible practice. That is, 'Facebook stalking' was not only accepted, but was an admissible commonplace practice.

As such, understandings of privacy were renegotiated by participants, constituted primarily through the broad social networks that come together through the site, alongside the conventions facilitating ambient intimacy. As a result of participants considered privacy practices, it often felt out of place when I asked to use specific Facebook data; participants, after all, felt consent had already been granted through the control of privacy settings, which determined if I had access to certain content. In one example, I messaged Elizabeth asking for consent to use a photo taken by her at Mardi Gras. Having not responded after a week, I sent another brief, apologetic message, again asking for consent. Despite Elizabeth often providing in-depth enthusiastic responses, she bluntly replied 'yep, of course, use anything you want. No need to ask.'

While it was clear that consent was differently interpreted in this space to that of the conventional hard copy form, I continued to openly and continually negotiate when using personal information, despite the practice feeling out of place and burdensome, for two reasons. First, I was not assured all participants always controlled privacy settings. And second, the practice of asking reemphasised the control and power I wanted participants to feel.

While I felt comfortable this process complied with normative Facebook practices, I am intrigued to apprehend how a university ethics committee might respond to this level of access to information. Particularly, considering that this information may appear private to the unacquainted.

Slippery conceptualisations of consent and privacy did render tensions between personal ethical stipulations and those of the university's ethics guidelines. Like Hodge and Lester (2006) I found institutional ethics protocols to lack awareness of the messiness of online methodologies. Driven by a feminist research ethics I did not generate a prescriptive methodology before fieldwork, rather I aimed to create an atmosphere of co-production with participants, once in the field (England, 2002). It was, however, necessary to lay out a formulaic methodology for ethics approval. Unsure of how fieldwork would unfold, I was not aware Facebook would be used so extensively. For this reason formal ethics approval only outlined the possibility of using social media for storytelling to reduce 
participant's burden of time, and a reduction in my own travel costs. It was made clear that no solicited responses would be sought, with online communication taking place only if initiated by participants.

Following university ethics protocols it is a requirement of the researcher to immediately report proposed changes. In practice, however, this was an impractical task because the methodology was quickly evolving individually with each participant, while the university ethics committee only met on a monthly basis, with an agenda deadline two weeks prior. Plainly, it was inconceivable to repeatedly freeze participant contact to report constantly shifting adjustments. It was clear, that the interception of an online methodology and feminist research ethic threatened, and raised doubts, around the practicalities of formalised ethics procedures.

Ambiguities of privacy required awareness of themes participants felt (un)comfortable to share. Particularly intimate storytelling took place in spaces deemed by participants to be more 'private'. In practice this too required open, ongoing discussions with participants around understandings of privacy, consent and themes covered when storying. It was vital to ensure participants felt in control to end, redirect, or move the storying to an alternative space. By way of example, Katie's storytelling was particularly forthcoming through Facebook. On her own terms, Katie initiated discussions around themes such as alcohol drinking practices, sexuality and gender politics. Yet, it was not until our face to face interview that Katie introduced stories regarding the politics of her current intimate relationship. Themes that were evidently incredibly emotional and personal, and consequently understood to be highly private. While a face to face interview was necessary to share these more private stories, Facebook storying and the face to face interview had a reciprocal relationship - while intimate stories were shared face to face, Katie disclosed that she would not have felt comfortable sharing personal experiences so quickly without the previously established Facebook relationship.

The site's drawbacks regarding privacy did not deter me from its productive possibilities. Continual (yet unobtrusive) communication, access to archived data and reciprocal ambient intimacy produced knowledge of commonalities between myself and participants, breaking down subject positions of 'stranger', 'researched' and 'researcher'. Possibilities to break down subject positions initiated trust and openness more easily and more quickly than with participants not communicating through the site. Moreover, ability to consider and construct online identity (through control of what is uploaded, and determining who has access to what), arguably self-empowers participants. Such abilities to construct online identity, have however, raised concern within critical technology studies around issues of representation - a discussion to which I now turn. 


\section{Representation}

Representation is a contested issue in online research. Capacity to construct representations of identity online through filtering and altering of uploaded data has led certain scholars to question the extent to which online performances reflect the identity of users (Robinson and Schulz, 2011). Alternative concerns highlight the gap between the self and one's ability to represent the self online (Brushwood Rose 2009). These issues have raised anxieties around the potentials for garnering insight through online representations of participant identity and narratives. Scholars counter to these viewpoints, however, importantly point out that delineations between on and offline representations are arbitrary because identity itself is a controlled, filtered, altered and presented performance (Hine, 2012; Kinsley, 2013). One becomes a subject through performance. Following from this premise, rather than there being issues with online representations of identity, online performances become a part of identity and bring identity into being. On this view, researchers need to remain alert to the particular affordances and conventions of an online site in influencing the ways identities are performed.

Working from this latter perspective I want to suggest that online representations of identity are more than non-problematic, undertaking fieldwork through Facebook actually offered opportunities to increase knowledge of participant's identities. This worked through three registers. First, Facebook is utilised as a space for social networking. It is produced in part through its entanglements with other spaces. Participants did not seek anonymity through the creation of an alias or radically alter identity performance. Facebook performances were based on already established relations and roles. The site, therefore, enabled opportunity to observe how such relations play out, in a way that alternative spaces were not accessible during fieldwork. Secondly, Facebook provided a platform for participants to control what they say, and for what they said to be seen by large numbers. I suggest an ability to control performance empowers individuals to present stories on their own terms. To this end Facebook provided insight to observe the performance of participants' identity politics (McLean and Maalsen, 2013). And finally, longer temporalities in the field afforded through Facebook facilitated heightened understandings of the nuances, repetitions, differences and paradoxes of participants' identities.

Exploring observations of David provides an ardent example. David manages a regional queer collective. In 2013 David organised for the collective to travel as a group to Mardi Gras. Undertaking two semi-structured interviews with David I came to understand the role of the queer collective and the ways the group conceptualised Mardi Gras. It was not until I became connected with David through Facebook, however, that I developed an understanding of the power and immensity of his 
supportive role within the collective, and home region more broadly. David utilised Facebook as a space to perform regional social activism - campaigning politically, raising funds for non-profits, organising community events, connecting individuals and more. During interviews David was too self-effacing to discuss the powerful role he performed; it only became known through observation of his relations with others, the presentation of his online identity and the time in the field afforded through Facebook.

\section{Storytelling}

Facebook is designed as a social space. The site's core being the dynamic social news feed (Robards, 2012). Experiencing the site requires engagement with other users through participation in commentary on friend's posts or initiating your own posts. There is an assumption that personal information will be shared. This affordance had important implications for the ways participants took part in storytelling. Storying generally took place through private messages, was informal and conversational, and shifted between synchronous and non-synchronous communication - as engagement threaded through participants' everyday lives.

While the functionality of the site as a social space facilitated openness and sharing of the personal, difficulties arose in unearthing the more reflexive and in-depth storytelling. This was particularly evident with Big Day Out participants. I propose that this implication resulted from the entanglement of three main factors. First, experiences shared through Facebook are subject to normative practice, and individual and collective construction. While the sharing of information through Facebook is intimate, it is also generally prosaic, banal and often random, rather than indepth, reflexive narrative. Second, Facebook brings together previously segmented networks (for example work colleges, parents, grandparents, school friends), requiring users to negotiate their performance in relation to the anticipated gaze from a number of disparate networks. And finally, market researchers have identified that while the ways individuals use Facebook is multifaceted, multitasking is common practice. Judd (2014) claims, for example, that $99 \%$ of Facebook sessions involve multitasking. Morpace (2010) similarly argues that Facebook use is integrated into daily practices by the majority of users (for example, $68 \%$ of users simultaneously check email, while $55 \%$ listen to music). I would also suggest multitasking includes simultaneously engaging with a number of Facebook friends and functionalities, rather than focus on one to one communication.

Practices of multitasking were evident through communication with Big Day Out participant, Matt. As a result of personal time pressures Matt conducted storying at work. During a number of 
conversations I noticed Matt also simultaneously engaging with other Facebook friends ${ }^{4}$. I postulate that generating in-depth, reflexive storytelling with Matt was particularly difficult because of his practices of multitasking in this space. Matt's responses were short, lacking reflective and emotive elements - not moving beyond descriptions of favourite bands, festival drinking practices and general likes and dislikes. Big Day Out participant's text and graphics chiefly featured bands, set lists, crowds/people/friends, planning and location during specific performances (cf. Figure 2).

Intriguingly, contrasting with Big Day Out respondents, Mardi Gras participants tended to be more reflexive when sharing festival stories. This may have resulted from the greater average age of Mardi Gras participants (early twenties to early forties, compared to Big Day Out's late teens to early twenties). Yet, more crucially this may have been driven by the political impetus of the event. Online content, for instance, predominantly drew attention to the contested positioning of Mardi Gras as political, commodified, outrageous, frivolous, and as a site of belonging. Text and graphics featured political messages, floats, travel companions and, rainbow flags and symbols. This was evident in Cam's Facebook post before journeying to Mardi Gras (Figure 3), which positioned the event as fun and wonderful, yet also crucially connected to his broader life journey and identity politics.

Ethical dilemmas arose around the use of 'private' messaging as a space for storytelling. Facebook is currently being sued for allegedly intercepting private messages, sharing data with advertisers (Feloni, 2014). Facebook claims this practice is not taking place. Whether this is occurring or not, the issue remains, by creating an account users are effectively granting Facebook permission to surveil and commodify data generated through private messaging for anything it desires. This is not only a Facebook issue; this is an issue relevant for fieldwork taking place through most online spaces.

Code, commodification and surveillance are covert. It was thus difficult to assess the extent to which this issue may have affected storytelling. Not one participant raised concerns regarding Facebook's surveillance of storying. Participants who had consented to this methodology were surprisingly apathetic when asked to consider issues of surveillance. Crucially, however, apathy was not a result of ignorance. Participants were fully aware of the ways personal data was being used, yet accepted privacy issues as a result of the social convenience and cultural affluence Facebook affords. Mel's response highlights the conflict between awareness of Facebook's surveillance and commodification of 'private' messaging, and the fear of missing out on the cultural capital afforded through the site:

Anna: Are you concerned about the way Facebook has access to, and sells info from your private messages?

\footnotetext{
${ }^{4}$ Facebook's news ticker enables real time access to friend's activities (posts, comments, likes etc.).
} 
Mel: Yeah, sure, of course, I think about it. It affects how I use it [Facebook] and makes me think I should just get rid of the thing [Facebook account] but if I don't log in for a few days I start thinking, hmm I wonder what I'm missing out on. It's like you don't want to be the first to leave the party, in case you miss out on something. There's nothing particularly special about Facebook, in comparison to other social media, but it just happens to be where everyone is, so I just put up with sort of hating it.

Facebook conversation, Saturday $22^{\text {nd }}$ March, 2013

As with negotiations of 'privacy' between researcher and researched (discussed above), considerations of surveillance and commodification further produced fluidity to normative conceptualisations of public/private, influencing how and what is shared through the space. While participants undertaking storying through Facebook were apathetic, issues of surveillance may have potentially deterred participants who initially declined online storytelling.

Considering these issues alongside the apathetic yet informed position of participants, I was left asking - what are my obligations in informing participants of Facebook's surveillance and commodification practices? And how does an ethic of consent tie into this, considering I possessed no power to control the use of participants' personal information (rather power was placed in the hands of those who own and design Facebook software - chiefly well educated, white, upper middle class, western, male individuals ${ }^{5}$ )? It was unrealistic to place responsibility on Facebook. After all, the social medium's obligations are to generate profit for shareholders, not protect the privacy of users. Rather, before commencement of methods, conversations took place with each participant, to discuss the site as a public space, and the potential ways data may be generated through private messaging. Through these discussions it emerged, that as with issues of researcher and researched privacy, participants understood the benefits and limitations of using this space for fieldwork, and the necessity to negotiate privacy and revelation through the storying process.

\section{Conclusion}

This paper stems from an interest in understanding the importance of festivals beyond the spatial and temporal limits of the event. This paper responds to a lack of work in geographical research exploring how online spaces shape knowledge production and the stories participants choose to share in varying ways, which depends on each site's unique social conventions and affordances. In

\footnotetext{
${ }^{5}$ Facebook's employee diversity is concerning. Nearly $70 \%$ of Facebook employees are male, $57 \%$ are white. Statistics become even less diverse when analysing statistics of technical employees (code creators) and senior level positions (Guynn, 2014). The company has come under attack for largely recruiting through top United States universities (primarily, Stanford and UC-Berkeley) (Pearlstein, 2014).
} 
responding to this gap, my aim was to illustrate the potential contribution online research tools can make to qualitative research. In this article, empirical material from a study of journeys to large metropolitan events has been used to consider the processes of fieldwork, and the production of stories, through the online space, Facebook. The practices of participants in the present study do not represent the fabric of Facebook independently; participants' practices and experiences, nevertheless, hint at the possibilities (and impossibilities) for geographers to undertake collaborative storytelling with participants through Facebook as a fieldwork site.

Ongoing engagement grants greater control to participants to present stories on their own terms and stimulates co-production as methodology and engagement evolve side by side. Yet, perhaps more importantly, the insight over longer temporalities and shifting spatialities afforded through Facebook facilitates heightened understandings of the nuances, repetitions, differences and paradoxes of identities, encounters and politics. Facebook, therefore, has the potential to allow for different ways of knowing, that cannot be ascertained in more orthodox research spaces.

Participant engagement in this space challenged the undertaking of conventional fieldwork practices. The slipperiness of conceptualisations of privacy in this space, for example, drew attention to the necessity of understanding consent as fluid and ongoing, rather than antecedent to fieldwork commencement. Transparent, consistent and open collaboration suggests a way researchers might account for such uncertainty, while also making use of the productive elements of Facebook as a site for storytelling, and geographical research more broadly. Crucially, however, reconceptualisation of consent within Facebook exposes potential obstacles university ethics committees may meet in responding to research moving into online spaces. 


\section{References}

Adam, P. and Ghose, R., 2003: India.com: the construction of a space between. Progress in Human Geography 27, 414-437.

Alexa., 2013: Alex Top 500 Global Sites. Retrieved: 14 April 2014 from www.alexa.com/topsites.

Bain, A. and Nash, C., 2006: Undressing the researcher: feminism, embodiment and sexuality at a queer bathhouse event. Area 38, 99-106.

Bakardjieva, M., 2005: Internet Society: The Internet in Everyday Life. Sage, London.

Berry, S., 2012: When Face-Stalking Turns Scary. Retrieved: 22 October 2014 from http://www.smh.com.au/lifestyle/life/when-facestalking-turns-scary-20120913-25ume.html.

Brown, R. and Gregg, M., 2012: The pedagogy of regret: Facebook, binge drinking and young women. Continuum 26, 357-369.

Browne, K., 2007: A party with politics? (Re) making LGBTQ pride spaces in Dublin and Brighton. Social and Cultural Geography 8, 63-87.

Browne, K., 2011: Lesbian separatist feminism at Michigan Womyn's music festival. Feminism and Psychology 21, 248-256.

Brushwood Rose, C., 2009: The (impossibilities of self representation: exploring the limits of storytelling in the digital stories of women and girls. Changing English 16, 211-220.

Cameron, E., 2012: New geographies of the story and storytelling. Progress in Human Geography 36, 573-592.

Crampton, J., Graham, M., Poorthuis, A., Shelton, T., Stephens, M., Wilson, M. and Zook, M., 2013: Beyond the geotag: situating 'big data' and leveraging the potential of the geoweb. Cartography and Geographic Information Science 40, 130-139.

Crawford, K., 2009a: Following you: disciplines of listening in social media. Continuum 23, 525-535.

Crawford, K., 2009b: These foolish things: on intimacy and insignificance in mobile media. In Goggin, G. and Hjorth, L. (eds) Mobile Technologies: From Telecommunications to Media. Routledge, New York, 252-266.

Crooks, V., 2006: 'I go on the internet: I always, you know, check to see what's new': chronically ill women's sue of online health information to shape and inform doctor-patient interactions in the space of care provision. ACME 5, 50-69.

Datta, A., 2008: Specialising performance: masculinities and femininities in a 'fragmented' field. Gender, Place and Culture 15, 189-204.

Dodge, M. and Kitchin, R., 2009: Software, objects, and home space. Environment and Planning A 41, 1344-1365.

Driscoll, C. and Gregg, M., 2010: My profile: the ethics of virtual ethnography. Emotion, Space and Society 3, 15-20.

Duffy, M., 2009: Festival and spectacle. In Kitchin, R. and Thrift, N. (eds) International Encyclopaedia of Human Geography, Amsterdam, Elsevier, 294-299.

Elwood, S. and Leszczynski, A., 2011: Privacy, reconsidered: new representations, data practices, and the geoweb. Geoforum 42, 6-15.

England, K., 2002: Interviewing elites: cautionary tales about researching women managers in Canada's banking industry. In Moss, P. (ed.) Feminist Geography in Practice: Research and Methods. Oxford, Blackwell, 200-213.

England, K., 2006: Producing feminist geographies: theory, methodologies and research strategies. In Aitkin, S. and Valentine, G. (eds) Approaches to Human Geography. Sage, London, 286-297.

Facebook., 2013: Facebook news room. Retrieved 14 April 2014 from http://newsroom.fb.com/.

Feloni, R., 2014: Facebook Sued for Allegedly using your Private Messages to Trigger Ads. Retrieved: 30/07/2014 from http://www.businessinsider.com.au/facebook-sued-for-allegedly-using-yourprivate-messages-to-trigger-ads-2014-1.

Gatson, S., 2011: Self-naming practices on the internet" identity, authenticity and community. Cultural Studies - Critical Methodologies 3, 224-235.

Geertz, C., 1973: The Interpretation of Cultures: Selected Essays. Basic Books, New York. 
Getz, D., 2010: The nature and scope of festival studies. International Journal of Event Management Research 5, 1-47.

Graham, M., Zook, M. and Boulton, A., 2012: Augmented reality in urban places: contested content and the duplicity of code. Transactions of the Institute of British Geographers 38, 464-479.

Gregg, M. and Driscoll, D., 2008: Message me: temporality, location and everyday technologies. Media International Australia, 128-136.

Guynn, J., 2014: Status Update: Facebook Not So Diverse. Retrieved 30/07/2014 from http://www.usatoday.com/story/tech/2014/06/25/facebook-diversity/11369019/.

Hammersley, M., 2006: Ethnography: problems and prospects. Ethnography and Education 1, 3-14.

Hine, C., 2005: Virtual methods and the sociology of cyber-social-scientific knowledge. In Hine, C. (ed) Virtual Methods: Issues in Social Research on the Internet. Berg, Oxford, 1-13.

Hine, C., 2012: Tales from Facebook. Sociological Review 60, 180-182.

Hodge, P. and Lester, J, 2006: Indigenous research? Journeys and possibilities of cross-cultural research in geography. Geographical Research 44, 41-51.

Johnston, L., 2005: Queering Tourism: Paradoxical Performances at Gay Pride Parades. London, Routledge.

Judd, T., 2014: Making sense of multitasking: the role of Facebook. Computers and Education 70, 194-202.

Kinsley, S., 2013: Beyond the screen: methods for investigating geographies of life 'online'. Geography Compass 7, 540-555.

Kitchin, R., Linehan, D., O'Callaghan, C. and Lawton, P., 2013: Public geographies through social media. Dialogues in Human Geography 3, 56-72.

Lafata, A., 2014: Stalking or Looking? The Difference Between Being a Creep and a User on Facebook. Retrieved: 22 October 2014 from http://elitedaily.com/life/facebook-looking-vs-facebookstalking/602509/.

Lee, Y., Chen, F. and Jiang, H., 2006: Lurking as participation: a community perspective on lurkers' identity and negotiability. Making a Difference: Proceedings of the $7^{\text {th }}$ International Conference on Learning Sciences. International Society of the Learning Sciences, Bloomington, 404-410.

$\mathrm{Li}, \mathrm{X}$. and Petrick, J., 2006: A review of festival and event motivation studies. Event Management 9, 239-245.

Lorimer, H., 2003: Telling small stories: spaces of knowledge and the practice of geography. Transactions of the Institute of British Geographers 28: 197-217.

Madge, C., 2007: Developing a geographers' agenda for online research ethics. Progress in Human Geography 31, 654-674.

McLean, J. and Maalsen, S., 2013: Destroying the joint and dying of shame? A geography of revitalised feminism in social media and beyond. Geographical Research 51, 243-256.

Morpace., 2010: Omnibus Report. Retrieved: 14 April 2014 from www.morpace.com/OmnibusReports/Morpace\%200mnibus\%20Report-Facebook.pdf .

Morrow, O., Hawkins, R. and Kern, L., 2014: Feminist research in online spaces. Gender, Place and Culture, DOI http://www.tandfonline.com/doi/abs/10.1080/0966369X.2013.879108.

Moss, P., 2002: Feminist Geography in Practice: Research and Methods. Blackwell, Oxford.

Nash, K., 2012: Goa hippy tribe: theorising documentary content on a social network site. Media International Australia 142, 30-40.

Nonnecke, B. and Preece, J., 2003: Silent participants: getting to know lurkers better. In Lueg, C. and Fisher, D. (eds.) From Usenet to Cowebs: Interacting with Social Information Spaces. Springer, Amsterdam, 110-132.

O'Connor, H., Madge, C., Shaw, R. and Wellens, J., 2008: Internet-based interviewing. In Fielding, N., Lee, R. and Black, G. (eds) The SAGE Handbook of Online Research Methods. SAGE Publications, London, 271-289.

Olive, R., 2012: 'Making friends with the neighbours': blogging as a research method. International Journal of Cultural Studies 16, 71-84. 
Pearlstein, J., 2014: The Schools Where Apple, Google, and Facebook Get Their Recruits. Retrieved: 30/07/2014 from http://www.wired.com/2014/05/alumni-network-2/.

Pegg, S. and Patterson, I., 2010: Rethinking music festivals as a staged event: gaining insight from understanding visitor motivations and the experiences they seek. Journal of Convention and Event Tourism 11, 85-99.

Picard, D. and Robinson, M., 2006: Remaking worlds: festivals, tourism and change. In Picard, D. and Robinson, M. (eds) Festivals, tourism and social change: remaking worlds, United Kingdom, Channel View Publications, 1-31.

Pickerill, J., 2007: 'Autonomy online': indymedia and practices of alter-globalisation. Environment and Planning A 39, 2668-2684.

Reichelt, L., 2007: Ambient intimacy. Disambiguity. Retrieved: 14 April 2014 from http://www.disambiguity.com/ambient-intimacy/.

Robards, B., 2012: Leaving Myspace, joining Facebook: 'growing up' on social networking sites. Continuum 26, 385-398.

Robinson, L. and Schulz, J., 2011: New field sites, new methods: new ethnographic opportunities. In Nagy Hesse-Biber, S. (ed) The Handbook of Emergent Technologies in Social Research. Oxford University Press, Oxford, 180-198.

Rose, G., 1997: Situating knowledges: positionality, reflexivities and other tactics. Progress in Human Geography 21, 305-320.

Ross, M., 2014: Facebook Turns 10: The World's Largest Social Network in Numbers. Retrieved: 14 April 2014 from http://www.abc.net.au/news/2014-02-04/facebook-turns-10-the-socialnetwork-in-numbers $/ 5237128$.

Schwanen, T. and Kwan, M., 2008: The internet, mobile phone and space-time constraints. Geoforum 39, 1362-1377.

Waitt, G. and de Jong, A., 2013: Embodied geographies of alcohol and the weekend in the Bega Valley, New South Wales, Australia. Leisure Studies 33, 116-132.

Wilson, M., 2011: Data matter(s): legitimacy, coding and qualifications-of-life. Environment and Planning D 29, 857-872. 
Table 1 Facebook conventions and affordances

Conventions

\begin{tabular}{|c|c|c|}
\hline Temporality & $\begin{array}{l}\text { Part of the cultural context of festivals and } \\
\text { events } \\
\text { Part of who many people are - crucial } \\
\text { element of identity construction } \\
\text { Practice of 'liking' and commenting on } \\
\text { 'friends' that one might not keep in contact } \\
\text { with outside of Facebook - draws } \\
\text { researcher and participant back into } \\
\text { conversation }\end{array}$ & $\begin{array}{l}\text { Used on the move - data captured in situ } \\
\text { Connection issues in large crowds } \\
\text { In the moment access to participant experience } \\
\text { Participant engagement and exchange takes place } \\
\text { over longer temporalities (enables 'thicker } \\
\text { descriptions' - compared to the often limited time } \\
\text { available conducting face to face fieldwork } \\
\text { Requires time to frame one's life as meaningful, a } \\
\text { certain literacy, and self-presentation }\end{array}$ \\
\hline $\begin{array}{l}\text { Power, privacy } \\
\text { and identity }\end{array}$ & $\begin{array}{l}\text { 'Ambient intimacy', users already sharing } \\
\text { intimate and personal information } \\
\text { regarding everyday life - breaks down } \\
\text { researcher/researched boundaries } \\
\text { Fluidity to understandings of 'privacy' - } \\
\text { requires renegotiations of consent and } \\
\text { what is shared }\end{array}$ & $\begin{array}{l}\text { Coding controls interaction with participants } \\
\text { Concealment and revelation concerns through } \\
\text { access to archived information }\end{array}$ \\
\hline Representation & $\begin{array}{l}\text { Increased knowledge of identity - through } \\
\text { observation of participant relations with } \\
\text { others, insight into the ways participants } \\
\text { wishes to be observed and increased } \\
\text { temporalities }\end{array}$ & $\begin{array}{l}\text { Entanglement of Facebook with other spaces } \\
\text { creates space for social networking - rather than } \\
\text { space to perform alternative identities }\end{array}$ \\
\hline Storytelling & $\begin{array}{l}\text { Social, informal and conversational } \\
\text { communication, however lacking in-depth, } \\
\text { reflexive narrative } \\
\text { Necessary to negotiate gaze from a } \\
\text { number of disparate networks } \\
\text { Tendency of users to multitask }\end{array}$ & $\begin{array}{l}\text { Functionality of site as a social space facilitates } \\
\text { sharing of personal information } \\
\text { Synchronous and asynchronous } \\
\text { Potential surveillance and commodification of } \\
\text { private messages }\end{array}$ \\
\hline
\end{tabular}

\section{Affordances}

